\title{
A Narrative Inquiry into Pedagogical Approaches that Support the Development of Transversal Skills in Engineering Students
}

\section{Dr. Michele Norton, Texas A\&M University}

Recent PhD graduate from Texas A\&M University. Currently working across four NSF funded grants related to STEM education and other funded grants related to Engineering Education and developing leaders in Engineering. Research interests include design-based learning, transversal skills, creativity, engineering education, holistic education, and teams.

\section{Dr. Behbood Ben Zoghi, Texas A\&M University}

Ben Zoghi is the Victor H. Thompson endowed Chair Professor of electronics engineering at Texas A\&M University, where he directs the College of Engineering RFID Oil \& Gas Consortium and teaches application of emerging technologies. Over the past 10 years, Zoghi has led or been involved in the development of many RFID and sensor implementation and solutions. He is a frequent speaker for association and industry events on RFID, wireless sensor network, technology applications in oil and gas, and petrochemical industries globally. 


\section{A Narrative Inquiry into Pedagogical Approaches that Support the Development of Transversal Skills in Engineering Students}

In 2013, UNESCO-International Bureau of Education, defined transversal skills as "skills that are typically considered as not specifically related to a particular job, task, academic discipline or area of knowledge and that can be used in a wide variety of situations and work settings." Other terms used across literature include soft skills, non-technical skills, leadership competencies, social and emotional intelligence. This research journey aimed to explore engineering students' perspectives on developing both the technical or discipline related skills along with the non-technical or transversal skills needed to be effective leaders within their professional landscape. In a survey done with large corporations in Canada, researchers found that leadership, people skills, and team-related skills are more important than the technical skills required to perform their job-related tasks when looking at overall long-term success within the corporation [1]. According to various surveys, transversal skills such as working in teams, communicating effectively, leading others, problem-solving and adaptability to be among the most desired traits employers are looking for [2]-[3]. The Engineering Competency Model (2015) developed through a collaboration between the American Association of Engineering Societies (AAES) and the U.S. Department of Labor (USDOL) outline many competencies that would fall within the transversal skills category: interpersonal skills, teamwork, creative thinking, critical thinking, decision-making, as well as many others. Included within their model specifically for leaders or managers were competencies such as delegating, supporting others, motivating and inspiring others, managing conflict, and team building.

As implied in the development of the Engineering Competency Model, (2015) as industry has been demanding that graduating engineers have both the technical and transversal skills needed to be successful, engineering education has been continually iterating on ways to support the industry's demand in an effective and efficient manner [4]. Some researchers have called for engineering education to consider emotional intelligence development within their educational structure, but fewer studies have looked at possible pathways to developing those skills within an engineer's educational experience [5]. This study seeks to explore the learner's (higher education students) perspective on utilizing emotional intelligence assessments, reflection and coaching as a path to crossing the boundary between the need to develop both the technical and transversal skills for achieving success in their professional career.

\section{Background}

With a call for engineering education to meet the evolving global and industry-focused demands of engineers, more research is needed to bridge the gap between what does industry demand of its employees and leaders and what are the pedagogical approaches that support building that bridge within higher engineering education. Beder [6] states that

the image of the engineer as a technically-inclined and socially introverted is increasingly outdated. Engineers manage socio-technological systems: they bring together, work with, coordinate, manipulate, and build upon various elements of a system which include not only things, but also social organizations, laws, financial and cost considerations, scientific theories, natural resources and public perceptions. (p.57) 
Preparing engineers and leaders for the professional landscape now requires development in integrative thinking, which engages both the intellectual and emotional domains [7]. Mayer and Salovey's revised definition of emotional intelligence also includes this integrative crossing between thought and emotion:

the ability to perceive accurately, appraise, and express emotions, the ability to access and/or generate feelings when they facilitate thought, the ability to understand emotion and emotional knowledge; and the ability to regulate emotions to promote emotional and intellectual growth [8].

Other emotional intelligence researchers, such as Goleman and Bar-on include not only the emotional and intellectual components but explicitly discuss the relational component of emotional intelligence. This view of emotional intelligence aligns with research on the capabilities that leaders need to be effective as they lead others and manage performance. The capabilities needed often span the cognitive or intellectual ability, intrapersonal or selfmanagement, interpersonal or relationship management [9]. To help learners develop capabilities across the three clusters, pedagogical strategies that build awareness, provide pathways to change, and support the transfer of new knowledge into their professional contexts are needed. For this study the use of emotional intelligence assessments, reflection, and coaching were utilized to support the leadership development of the learners.

\section{Emotional Intelligence Assessments}

There are a variety of emotional intelligence assessments that an individual can take to gain insights into themselves and begin the journey of self-awareness. For this study, the Emotional Quotient Inventory (Eq-i) 2.0 was utilized. Bar-On's EQ-i 2.0 is a self-assessment that measures 15 constructs embedded within his model of emotional intelligence: self-regard, self-actualization, emotional self-awareness, emotional expression, assertiveness, independence, interpersonal relationships, empathy, social responsibility, problem-solving, reality testing, impulse control, flexibility, stress tolerance and optimism. These subscales are then grouped together under an umbrella to create a composite score for 5 overarching categories: selfperception, self-expression, interpersonal, decision-making, and stress management.

Emotional intelligence assessments are one tool that can provide a different perspective for the learner to evaluate their strengths and areas of growth needed to be more effective as a leader. Duval and Wickland's (1972) theory of self-awareness suggest that you need different vantage points to look at oneself so that you can see both yourself and how others might see you [10]. Key dimensions of self-awareness include "sensitivity to inner feelings, recognition of one's positive and negative attributes, introspective behaviors, tendency to picture or imagine oneself, awareness of one's physical appearance and presentation; and concern over the appraisal of others" [10]. By supporting learners in developing self-awareness, it provides a gateway to their potential success as a leader [11]-[13]. It provides that gateway to effective leadership because self-awareness provides both the foundation for supporting learners to being open to change and it is necessary for developing higher levels of emotional intelligence [14]. The power of opening the door to change through self-awareness is probably best summed up by the Chinese philosopher Lao Tsu who said, "knowing others is intelligence; knowing yourself is true wisdom...mastering others is strength; mastering yourself is true power" (n.p.). 


\section{Reflection}

Grounded in the work of Dewey and his belief that reflection is the "active persistent and careful consideration of any belief or supposed form of knowledge in light of the grounds that support it and the further conclusions to which it tends" [15], reflection has become a critical strategy for personal growth and learning. Reflection provides the space for challenging your current beliefs as evident in your experiences, so that you can imagine a changed self. For Argyris and Schon (1978) engaging in dialogue that questions the validity of underlying assumptions and beliefs about leadership, they can reflect on and inquire into learning to lead [16]. By changing your conceptual perspective[17], you are engaging in what Mezirow [18] coined transformational learning. By focusing on knowing through experience and critical reflection, transformative learning can lead to growth and empowerment [17][18]. Transformational growth across all aspects of being human (physical, emotional, intellectual, and social) are critical to the process of self-actualization and it is in self-awareness and reflection that you create the capacity for self-actualization, so awareness and reflection of oneself must be done beyond the bounds of solely the cognitive intellect[19]-[21].

\section{Coaching}

Research has shown that emotional intelligence has a substantial impact on leader success, and industry-based organizations are making significant financial investments in executive coaching for their leadership candidates to help develop their emotional intelligence [22]-[26]. While organizations are investing in the perceived potential of executive coaching to develop emotional intelligence skills as a pathway to effective leadership, research is still sparse despite the growth and demand for it in industry [27]. With an understanding that transformational change becomes evident when there is a "fundamental shift" to themselves, it must go beyond the intellectual insight and include behavioral change within their personal and professional landscapes [28]. In a meta-analysis conducted by Theeboom, Beersma, and E.M. van Vianen [29] on the effects of coaching on individual level outcomes within their professional context, they found that coaching can be effective even with a few sessions, but they did find that the more coaching sessions increases the conditions for more powerful changes from the coaching. They equated this with research on deeper learning or transformative learning [17] and it's finding that this type of transformation only occurs with an adequate opportunity for experience and critical reflection.

\section{Method}

Narrative inquiry is an experientially based methodology built upon the belief that experience happens narratively [30]. It usually begins "with an interest in a particular phenomenon... and try to make sense of the practice from the perspective of the participants, researcher and practitioner" [31]. For this study, narrative inquiry was utilized as both the method and the methodology to study the pedagogical experience as story [32]. Narrative inquiry opens the door to capturing the nuances of small incidents and encounters that are important when studying human experience [33] and gives value to context as you study lived experiences. Paying attention to those nuances or small incidents across the participants' lived experiences can provide insights to the very personal journey of developing transversal skills. 
Participants in this study are 29 students enrolled in an undergraduate course on Engineering Leadership at a Tier 1 University. The course has an intentional focus on the awareness of both the technical and transversal or non-technical skills needed to be competitive as leaders in the engineering field. As part of the leadership development, students engage in self-assessment, learning modules, coaching, reflection and experiential learning adventures that are designed to build their self-awareness and the transversal skills related to being an effective leader. Lessons learned from the self-assessment (EQ-I 2.0) and course material are immediately applied in their personal and professional landscapes as they focus on growing and developing their capacity to lead self and others. In this study, by narratively exploring their experience, we uncovered their perceptions on the use of self-assessments, reflection, and coaching in their leadership development journey and how these skills are impacting them in both their personal and professional contexts. The 'truthlikeness' of this study follows the research method line of narrative inquiry's belief that it can be developed through the 'narrative resonances' [34] across data sources, but it is ultimately the "readers who judge the extent to which our narrative accounts... [are] trustworthy."

\section{Data}

The data for this study includes 29 students pre and post-course EQ-i 2.0 assessments, along with their open-ended surveys, long-term projects, and interviews and focus groups. The data will first be looked at across the participants views of the EQ-i 2.0 assessment, use of reflections, and coaching as pathways to their personal and professional growth as future leaders in engineering. Next, it will be looked at in terms of the participants perceptions on how this course impacted them across their personal and professional landscapes.

\section{Emotional Intelligence Assessments}

Students were given the EQ i 2.0 assessment at the very beginning of the course and again at the conclusion of the course. Figure 1 captures the average of the scores prior to the coure and then again at the end of the course.

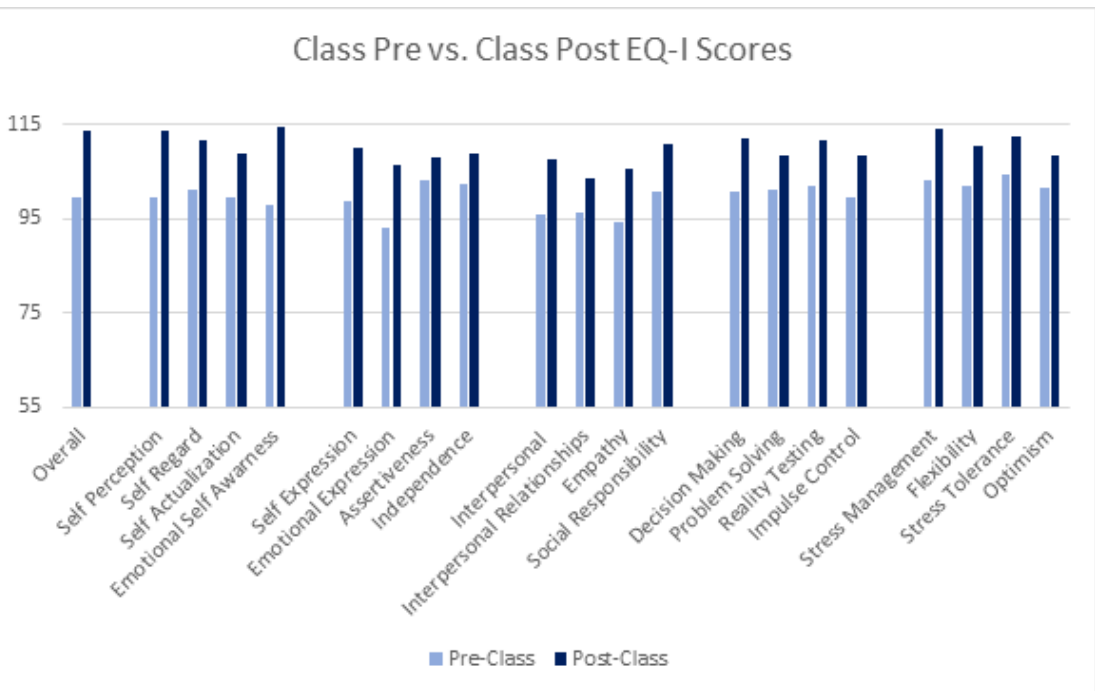

Figure 1. Pre and Post EQ-i 2.0 Scores. 
A paired-samples t-test was conducted to compare students' pre-Engineering Leadership course, EQ-i 2.0 scores and the post-Engineering Leadership scores. There was a positive statistically significant difference between the pre and post-tests at a $p<.01$ for the students overall EI score, self-perception composite, self-expression composite, decision-making composite, and stress management composite and a $\mathrm{p}<.02$ for the interpersonal composite. All the subscales within each composite score were also statistically different at the $p<.05$ level. The results suggest that engaging in an Engineering Leadership course can positively impact the development of transversal skills. As students reflected on the assessment, many discussed how it made them more aware of their strengths and areas of growth. The remaining part of this paper will be devoted to the stories shared by the participants on their perspective of how they changed and their thoughts on some of the pedagogical approaches utilized in the course.

When sharing their impressions of the EQ-i 2.0 assessments, students often discussed how it provided a window into their areas of strength and areas they might need to work on. One student responded, "it provided a framework for analyzing and improve my EI competency traits." Another student responded, "I discovered more about myself that I previously had no idea was there." As one student unpacked their impression of the EQ-i assessment, he stated:

Honestly, I was shocked to see on my first EQ test that my self-regard was one of my highest competencies. Since freshman year after a bad break-up, I have had growing insecurities which have been detrimental to success in my academic and personal lives. It helped me to be aware of my thoughts and actions, and how this...[I can] develop my character and how I interact with others.

As evident in their responses, the assessment provided a different window into themselves and their past, but for many it also sparked the imagination of a potential new door to walk through in the future. To be transparent, there were a few that found the assessment to be accurate but felt it did not give any new insights. They described the findings on the assessment as "exactly what they expected" and stated that it "provided nothing I didn't already know."

\section{Reflection}

When many of them shared stories around the written reflections for the class, they were filled with anxiety and fear. One student was worried about "getting a B because of my poor writing skills." Another student shared, "I sucked at writing and got caught up in how well I wrote and not the content...people did what the grader wanted to hear and not about them...it was frustrating because others would not do the work, like complete the interviews, but are a better writers and would get a higher grade and that sucks." One student felt the length of reflections was "too long and was just a waste of time trying to reach the page count....I would write what I think they would accept for a good grade instead of what I feel" A different student gave a slightly different perspective, "I am not a strong writer because grammar gets me...with the reflections when I can't get to the page count, it makes me think deeper...for example, with empathic listening, I never thought I applied it until I started reflecting and realized that I was applying things I was learning from class."

While many mentions the anxiety around the writing and grading, they still did also mention some of the positive or insightful aspects of reflection. One student stated, "I think they 
helped a lot with helping me to be self-aware...like how did I really think and act...and how can I improve upon that for the future." Despite this student having a negative view of completing reflections, when asked what advice he would give for future students, he stated, "take the reflections as a chance for growth instead of a grade, reflect more heavily on yourself instead of the content or mechanics...don't worry about the grade." When reflecting on their responses holistically, what stuck out to me, the researcher, was the word reflection initially sparked fear and anxiety around the writing, but the students that could look past that fear and the connection it had to their grade, also shared about the power of reflection to support building their awareness and capacity for change. How do we allow students to experience the power of reflection without the anxiety of the writing and being graded on their writing?

\section{Coaching}

After taking the first assessment, students met with the professor for a debriefing of the assessment results and a coaching session to help them identify their areas of focus for the semester. One student reflected back on the coaching as a place where they felt they could have the voice that they do not have in class: "I am not super vocal in class. I feel like there's a lot of other people like that...so where you're just in that one-on-one situation you can kind of get more real and share things you might not want to share in a class setting." He went on to say, "I saw coaching as a place where I wanted advice, but it helped me to become more self-aware. I wish I had more coaching sessions during the semester." Another student who hated the reflections, felt that meeting with the coach "caused me to be more reflective because it is more natural to talk than to type." The students who spoke negatively about coaching mentioned feeling judged and were uncomfortable discussing their personal lives with the coach.

\section{Personal Impact Stories}

As students shared stories on their perception of how this course impacted their lives, they often mentioned the impact it had on their relationships with family and friends. A few of those narratives will be shared in this section. One student shared how it dramatically changed their life, for the first time "my dad and I have something between us now. It may not be the perfect father-son relationship, or even close to that yet, but it's a good start." Another student shared, "I have talked more with classmates and expressed myself a little more. I have been able to open up more to my family, but I am too scared of my mom's judgement to want to continue to be more emotionally expressive." Another student also shared how it "helped me to be more expressive and open in my personal life with those I am close with." Some students talked about their relationship with a significant other. A student shared how "it has helped deepen my relationship with my girlfriend and has made me more aware of my emotions and willingness to share them with her. It has helped me to better be able to deal with my emotions rather than trying to ignore them. One student described the course as life-changing "because I re-evaluated decisions I made when I was younger, and I feel like I have the freedom to plan a different future." At no point during the course, did the professor tell students they needed to repair a relationship, but many across the stories shared took their new self-awareness and awareness of others to attempt to re-build or deepen a relationship with someone they obviously cared about. 


\section{Future Professional Impact}

Some students discussed how this course would impact them as future leaders in the engineering field. Figure 2 captures some of the themes across their responses.

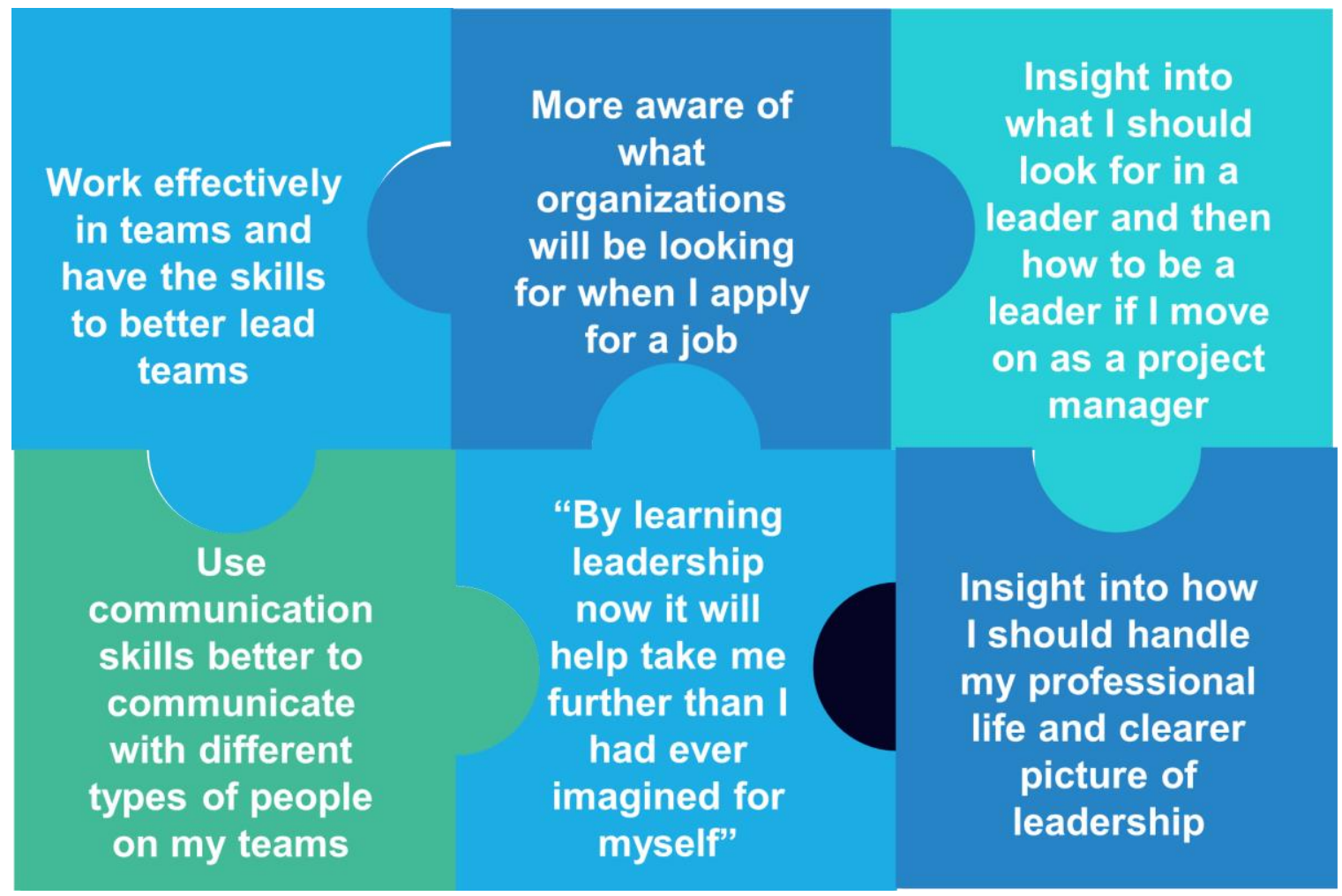

Figure 2. Professional Impact of Engineering Leadership Course

For some it gave them a clearer picture of what their professional future might be, but for many students in the class they talked about the impact in terms of the transversal skills that many industry professionals are hoping higher education develops, such as teamwork, adaptability, interpersonal relationship skills, conflict management, time management, and communication. Through some of the stories they shared, you can imagine what they would have looked like in their future professional context and the potential of what they might look like based on their new awareness. One student shared, "I am more aware of what I say and think when in conversations and with awareness of the EI competency of impulse control as my weakness, it has helped me to change a lot in my actions." Without this awareness, consider how their lack of impulse control would impact their future career. Another student shared, "I have learned a lot more about myself and I've learned I can be a bit too logical or a "stick in the mud" with a lot of things...I have begun working on interpersonal skills and being more empathetic as I try to move away from my cynical thoughts." Imagine how this person might show up different for their first job and how this awareness potentially opens up a different future. While these students are not currently living as their future professional self, they all were able to explore how they might be a better leader because of the topics explored during this class. While no one course can fully develop these competencies in students, as the development of these competencies in a lifelong endeavor, the students do suggest that they have a new lens that will 
help them to understand their behaviors and how they impact others, which is the beginning of change.

\section{Discussion}

This study took place over a semester course as 29 students embarked on the journey of learning more about themselves through the lens of emotional intelligence and leadership skills, but for many students it gave them a glimpse of a whole new future. The EQ-i 2.0 assessment was for many a window into their inner self that they had not peeked through before. While the technical writing component of the reflection created a negative reaction, some students were still able to see the value in getting them to think more deeply on their thoughts, emotions, and actions and how their could look a little different if they made some changes. The coaching sessions provided them a critical friend that challenged them to be more self-aware in places they might not have meandered to on their own, and for many students they craved more coaching sessions. The underlying principles of holistic education are that is must address the whole person, specifically the process of self-actualization, it must allow for individuals to understand that they are part of an interconnected system, and the educational experiences must elicit a transformation of consciousness that leads to a greater understanding of and care for self and others [35]. The path of transformation or the journey to self-actualization is said to begin with self-awareness [20]. The deepening of the students' self-awareness was evident across their reflection of the pedagogical approaches of utilizing emotional intelligence assessments, reflection and coaching. Acknowledging that no class can help a student obtain selfactualization, but a class that helps students develop a deeper level of self-awareness provides them the beginning to a path that might not otherwise exist.

At the intersection of personal assessments, reflection, and coaching, this study shared the narratives of students changing behavior and rewriting their future story. Resonance across their stories showed attempts at repairing a relationship with a parent or roommate, or making different choices, such as the participant who was trying not to be a "stick in the mud." While this study is not meant to be generalizable, just as no narrative inquiry based research seeks to be, it does seek to give voice to the learners' and their perceptions of a course that has opened some of them up to a new way of knowing, doing and being, and becoming their best-loved self [36]. For the graduates to become authentic leaders within the engineering field, they must achieve "authenticity...through self-awareness, self-acceptance, and authentic actions and relationships" [37]. Authenticity involves both an awareness of self and awareness of others, critical components of emotional intelligence development. Opportunities within the higher education experience need to provide the pathway for future leaders in engineering to begin or continue the path to authenticity.

In a systematic review comparing engineering skills required by the engineering accreditation bodies and the Industrial Revolution 4.0 skills required of graduates, researchers found a gap of seven skills: analytical thinking and innovation, active learning and learning strategies, creativity, originality and initiative, technology design and programing, critical thinking and analysis, emotional intelligence, and system analysis and evaluation [38]. Just as different skills are being required of recent graduates by industry, managers in engineering are no longer hired solely for their technical skills because without the social skills and selfleadership abilities they were unsuccessful [39]. Schein claims that analytical, inter-relational, 
and emotional competence are needed to navigate the emotionality of the professional landscape [40]. As we seek to better prepare our engineering graduates and future leaders for the demands of industry, more research is needed on how we can cross boundaries to better develop those transversal skills within the higher education context, as well as how the development of those skills impacts their leadership styles. 


\section{References}

[1] A. Hewitt, "Developing Canada's future workforce: a survey of large private-sector employers," Business Council Canada, March, p. 22, 2016.

[2] Gallup, "The State of the Global Workplace," Methods, 2010.

[3] NACE, "Job Outlook 2018," 2018.

[4] B. Schulz, "The importance of soft skills: Education beyond academic knowledge.," no. June, pp. 146-155, 2008.

[5] B. Tekerek and M. Tekerek, "Emotional intelligence in engineering education," Turkish J. Educ., vol. 6, no. 2, pp. 88-88, 2017.

[6] S. Beder, The new engineer : management and professional responsibility in a changing world. Sharon Beder. Macmillan Education Australia, 1998.

[7] R. Martin, "How Successful Leaders Think. (cover story)," Harv. Bus. Rev., vol. 85, no. 6, pp. 6067, 2007.

[8] J. D. Mayer and P. Salovey, "What is emotional intelligence?," in Emotional Development and Emotional Intelligence, P. Salovey, Ed. New York, NY: Basic Books, 1997, pp. 3-31.

[9] E. P. Gilmore, "Emotional intelligence for engineers," vol. 62, no. 6, 2008.

[10] S. Duval and R. A. Wicklund, A theory of objective self awareness. [by] Shelley Duval and Robert A. Wicklund. Academic Press, 1972.

[11] D. Goleman, "Emotional intelligence: Issues in paradigm building," in The emotionally intelligent workplace, C. Cherniss and D. Goleman, Eds. San-Francisco: Jossey-Bass, 2001, pp. 13-26. [11]

S. L. Stokes, "Emotional intelligence," Inf. Syst. Manag., vol. 21, no. 2, pp. 91-96, 2004.

[12] T. De Vreede, G. J. De Vreede, G. Ashley, and R. Reiter-Palmon, "Exploring the effects of personality on collaboration technology transition," Proc. Annu. Hawaii Int. Conf. Syst. Sci., pp. 869-878, 2012.

[13] D. Goleman, Working with Emotional Intelligence. New York: Bantam Books, 1998.

[14] J. Dewey, Experience and education. by John Dewey. New York : Macmillan, 1938., 1938.

[15] E. M. Boyd and A. W. Fales, "Reflective Learning: Key to Learning from Experience," J. Humanist. Psychol., vol. 23, no. 2, pp. 99-117, Apr. 1983.

[16] Argyris, C. \& Schon, D., Organizational Learning: A Theory of Action Perspective. AddisonWesley Publishing Co, 1978.

[17] J. Mezirow, Transformative dimensions of adult learning. 1st ed. Jack Mezirow., 1st ed. JosseyBass, 1991.

[18] J. Mezirow, Learning as transformation : critical perspectives on a theory in progress. JosseyBass, 2000.

[19] S. Mahmoudi, E. Jafari Associate Professor, H. Ali Nasrabadi Associate Professor, and M. Javad Liaghatdar Associate Professor, "Holistic Education: An Approach for 21 Century," Int. Educ. Stud., vol. 5, no. 2, 2012.

[20] R. Bar-On, "Emotional intelligence: An integral part of positive psychology," South African J. Psychol., vol. 40, no. 1, pp. 54-62, 2010.

[21] D. Goleman, Emotional intelligence. Bantam Books, 1995.

[22] R. E. Boyatzis, "Managerial and Leadership Competencies," Vis. J. Bus. Perspect., vol. 15, no. 2, pp. 91-100, 2011. 
[23] R. E. Boyatzis, E. C. Stubbs, and S. N. Taylor, "Learning Cognitive and Emotional Intelligence Competencies Through Graduate Management Education.," Acad. Manag. Learn. Educ., vol. 1, no. 2, pp. 150-162, 2002.

[24] V. Dulewicz and M. Higgs, "Can emotional intelligence be developed?," Int. J. Human Resource Management, vol. 15, no. 1, pp. 95-111, 2004.

[25] D. Goleman, Leadership : the power of emotional intelligence : selected writings. 1st ed. by Daniel Goleman., 1st ed. More Than Sound, 2011.

[26] B. G. Sadri, "Emotional entrance and leadership development," Public Pers. Manage., vol. 41, no. 3, pp. 535-549, 2012.

[27] D. Burt and Z. Talati, "The unsolved value of executive coaching: a meta-analysis of outcomes using randomized control trial studies," Int. J. Evid. Based Coach. Mentor., vol. 15, no. 2, pp. $17-$ 24, 2017.

[28] P. Cranton and E. Kasp, "A response to Michael Newman's "Calling Into Question: Some Mutinous Thoughts "," Adult Educ. Q., vol. 62, no. 4, pp. 393-398, 2012.

[29] T. Theeboom, B. Beersma, and A. E. M. van Vianen, "Does coaching work? A meta-analysis on the effects of coaching on individual level outcomes in an organizational context," J. Posit. Psychol., vol. 9, no. 1, pp. 1-18, 2014.

[30] D. J. Clandinin and F. M. Connelly, Narrative inquiry: experience and story in qualitative research. 1st ed. D. Jean Clandinin, F. Michael Connelly. San Francisco, Calif. : Jossey-Bass, [2000], 2000.

[31] F. M. Michael Connelly and D. J. Jean Clandinin, "Narrative and Education," Teach. Teach., vol. 1, no. 1, pp. 73-85, 1995.

[32] F. M. Connelly and D. J. Clandinin, "Stories of Experience and Narrative Inquiry," Educ. Res., vol. 19, no. 5, pp. 2-14, 2007.

[33] E. Estola and L. Syrjälä, "Chapter 8 Narrative Research: From the Margins to Being Heard," in From Teacher Thinking to Teachers and Teaching: The Evolution of a Research Community, vol. 19, Emerald Group Publishing Limited, 2013, pp. 157-173.

[34] C. Conle, "Resonance in Preservice Teacher Inquiry," Am. Educ. Res. J., vol. 33, no. 2, pp. 297325, 1996.

[35] R. Miller, "Introducing Holistic Education: The Historical and Pedagogical Context of the 1990 Chicago Statement," Teach. Educ. Q., vol. 19, no. 1, pp. 5-13, 1992.

[36] C. J. Craig, "Teacher education and the best-loved self," Asia Pacific J. Educ., vol. 33, no. 3, pp. 261-272, 2013.

[37] W.Gardner, B.Avolio, F. Luthans, D. May, \& F. Walumbwa, "Can you see the real me? A selfbased model of authentic leader and follower development," The Leadership Quarterly, vol. 16, pp.343-372, 2005.

[38] F. Mohd Kamaruzaman, R. Hamid, A. A. Mutalib, and M. S. Rasul, "Comparison of engineering skills with IR 4.0 skills,” Int. J. online Biomed. Eng., vol. 15, no. 10, pp. 15-28, 2019.

[39] P. Lappalainen, "Predictors of effective leadership in industry - should engineering education focus on traditional intelligence, personality, or emotional intelligence?," Eur. J. Eng. Educ., vol. 40, no. 2, pp. 222-233, 2015.

[40] E. H. Schein and F. von Ameln, "Relationships as a key to change. Ed Schein on the legacy and future of Change Management," Grup. Interaktion. Organ. Zeitschrift fur Angew. Organ., vol. 50, no. 2, pp. 141-144, 2019. 